\title{
CAPÍTULO 09: ISOTERMA DE SORÇÃO DE UVA ARRA 15® DESIDRATADA E ARMAZENADA EM DIFERENTES EMBALAGENS
}

\section{CHAPTER 09: GRAPE SORRERM ISOTHERM ARRA 15® DEHYDRATED AND STORED IN DIFFERENT PACKAGES}

\author{
Joselane Nascimento da Silva ${ }^{1}$; Iasmim Pereira Oliveira ${ }^{2}$; Nailton Macedo de Albuquerque \\ Junior $^{3}$; Aurianna Barros Coelho ${ }^{4}$; Silvana Belém de Oliveira Vilar ${ }^{5}$
}

\section{Resumo}

O Brasil é o $3^{\circ}$ maior produtor de frutas no mundo, sendo que a cada ano vem se destacando na variedade de vegetais produzidos. Como exemplo, temos a inserção de novas variedades de uvas dentre elas a Arra $15^{\prime}($, na região do Vale do São Francisco. No entanto, devido a elevada exportação dessa fruta, uma boa parte considerada imprópria é descartada, por não apresentar o padrão necessário. Dessa forma, a busca por tecnologias adequadas para reduzir essas perdas é de extrema importância, como por exemplo, a elaboração de uvas-passas atrelado ao uso de embalagens eficientes. Sendo assim, este trabalho objetivou comparar o comportamento de uvas passas de 'Arra $15^{\prime}(\mathbb{}$ ' armazenadas em duas distintas embalagens por 30 dias. As uvas in natura foram pré-tratadas com $\mathrm{NaOH}$ a $1 \%$, secas em Air fryer e armazenadas em bandejas de poliestireno (PS) com auxílio do filme de cloreto de polivinila (PVC) e em Polietileno de baixa densidade (PEBD). Após as análises, concluiu-se que a embalagem de PEBD apresentou maior estabilidade de isoterma de sorção, além da composição centesimal da fruta não ter sido alterada de forma significativa após processamento.

Palavras-Chaves: Conservação, Isoterma, Redução de perdas, Secagem, Tecnologia.

\begin{abstract}
Given the diversity of fruits in Brazil, the country is the 3rd largest producer and increases its cultivation each year, as the insertion of new varieties of grapes (Arra $15^{\prime} \circledR$ ) in the region of the São Francisco Valley, because they present good characteristics not only for consumption but also for processing. However, due to the high export of this fruit, a good part considered improper is discarded, for not presenting the necessary pattern. Therefore, the search for adequate technologies to reduce these losses is of extreme importance, such as the elaboration of raisins linked to the use of efficient packages. Therefore, this work aimed to produce 'Arra $15^{\prime} \AA$ raisins evaluating loss of mass, isotherm of sorption and physical-chemical composition of this agricultural product. To carry out the work, Airfryer drying was used along with pretreatment with $1 \% \mathrm{NaOH}$, and later stored in packages of Ps+PVC and LDPE for 30 days. After the analyses, it was concluded that the LDPE package showed greater stability of sorption isotherm and that the centesimal composition of the fruit was not significantly altered after processing.
\end{abstract}

Keywords: Conservation, Isotherm, Loss reduction, Drying, Technology.

\footnotetext{
${ }^{1}$ Graduada em Tecnologia em Alimentos, Instituto Federal do Sertão Pernambucano, joselanens13@hotmail.com

${ }^{2}$ Graduada em Tecnologia em Alimentos, Instituto Federal do Sertão Pernambucano, mimuefs@gmail.com

${ }^{3}$ Graduado em Tecnologia em Alimentos, Instituto Federal do Sertão Pernambucano, junior.nailton@ gmail.com

${ }^{4}$ Mestre em Horticultura, Professora Instituto Federal do Sertão Pernambucano, aurianna.coelho@ifsertao-pe.edu.br

${ }_{5}^{5}$ Doutora em Tecnologia em Alimentos, Professora do Instituto Federal do Sertão Pernambucano, silvana.belem@ifsertaope.edu.br
} 


\section{Introdução}

Numa escala mundial, o Brasil se encontra em $3^{\circ}$ lugar no ranking de produção de frutas, por apresentar uma grande diversidade tanto de frutas frescas como processadas (ALAMAR et al., 2016), com aproximadamente 45 milhões de toneladas por ano, dos quais $65 \%$ são vendidos no mercado interno e 35\% no mercado externo (EMBRAPA, 2019). Dados da ABRAFRUTAS (2020), mostram que a produção de frutas atingiu um nível de crescimento de $16 \%$ nas exportações de frutas no ano de 2019, onde 980.000 toneladas foram exportadas, em comparação com 848.000 toneladas em 2018. O principal é a exportação de manga com aumento de $30 \%$ nas exportações, $27 \%$ de melão, $19 \%$ de uvas e $10 \%$ de limões.

Devido à variedade de frutas, na região no Submédio do Vale do São Francisco, é evidente que vêm sendo introduzidas diversa cultivares de uvas, principalmente do tipo sem sementes, devido à preferência dos consumidores de diversos mercados, apontada a partir da década de 1990, bem como aos melhores preços adquiridos no mercado externo (LEÃO et al., 2011), o qual é o destino de uma fração importante da uva cultivada nesta região.

A partir dessas novas cultivares inseridas na produção frutífera do Vale do São Francisco, pode-se encontrar a variedade Arra $15^{\prime}\left({ }^{\circledR}\right.$. A produção em geral busca a designação de métodos de cultivo adequados para as circunstâncias regionais, assim como novos para acrescentar características, aperfeiçoar a qualidade da uva para o consumo in natura e determinar o ponto de colheita adequado à comercialização, visto que é uma variedade que apresenta propriedades como abundantes bagas, sem sementes e atraentes, com uma tonalidade de casca verde-clara e brilhante, em cachos de dimensão média a grande (KARNIEL; GIUMARRA, 2011).

Mello (2016) relatou que do cultivo de uva do país, 52,12\% neste ano foi usada para processamento, principalmente na forma de vinho, suco de frutas e derivados, e o restante para consumo fresco. Os dados de VITIBRASIL (2016), confirmam que o volume de processamento dessa forma seca de frutas ainda é muito baixo. Em 2015 dados mostram que o Brasil importou da Argentina, Estados Unidos, Chile, Emirados Árabes Unidos e Irã e outros países produtores de uva, um total de cerca de 24,8 toneladas de uvas - passas, o gasto total é de cerca de 40,6 milhões de dólares. O principal motivo da importação é que o país possui a menor área de plantio de trepadeiras sem sementes (mais adequadas para as passas), resultando em suprimento insuficiente desse tipo de uvas desidratadas.

A relevância da ciência e tecnologia de alimentos está no desenvolvimento de tecnologias e processos que possam diminuir perdas, principalmente para aumentar o suprimento de alimentos e garantir sua durabilidade a extenso prazo em termos de qualidade 
SILVA, J. N. et al.

(NESPOLO, 2015; GAVA, 2008).

A produção de uva- passas é um método alternativo para reduzir as importações e reduzir as perdas pós-colheita. Segundo Costa et al. (2015), o uso de bagas excedentes e de alta qualidade para a produção de uva - passas, pode diminuir os rendimentos e é uma opção de mercado para os produtores de uvas de mesa.

De acordo com Feiden et al. (2015), a secagem ou desidratação é uma tecnologia de conservação que reduz a umidade em frutas ou vegetais e minimiza a possibilidade de degradação microbiana, transformação enzimática e oxidação sem perder cor, aroma, sabor e textura. Para obter uvas - passas, a fruta passa por um processo de secagem ou desidratação.

A secagem possivelmente é um dos métodos mais antigos de preservação de alimentos pós-colheita empregados pelo homem. Este processo baseia-se na retirada de água de um material, com transferência de calor e massa, ou seja, conserva o material restringindo a umidade presente, sendo uma tecnologia de baixo custo que geralmente leva a poucas alterações sensoriais e nutritivas (ONWUDE et al, 2016).

A secagem é um processo amplamente utilizado na indústria de alimentos, pois proporciona o desenvolvimento de novos produtos com elevada vida útil (MACIEL et al., 2017). A conservação pelo processo de secagem está relacionada ao fato dos microrganismos, das enzimas e de todo o mecanismo metabólico necessitarem de água para realizar suas atividades (MARTINAZZO et al.,2007).

Dentre os processos de secagem existentes na literatura têm-se a secagem pelo air fryer, o qual se obtém produtos sem comprometer suas características organolépticas, além de ser uma técnica alternativa e prática para estimar a matéria seca de alimentos volumosos utilizados em confinamentos.

Esse equipamento dispõe de um ventilador interno, combinando altas taxas de convecção e transferência de calor por radiação, com isso o ar quente circula através do conjunto do motor do ventilador para cavidade do equipamento, onde o ar quente é dirigido de uma maneira em que um fluxo de gás turbulento colide, diretamente, com alimento proporcionando a secagem acelerada do produto alimentício. $\mathrm{O}$ ar também é distribuído uniformemente e as alterações na qualidade do produto são minimizadas devido à sua cavidade cilíndrica (TERUEL, 2015).

A capacidade dos alimentos de absorverem umidade, ou seja, a sua higroscopicidade, que está relacionada à sua estabilidade física, química e microbiológica, é indispensável para avaliar o comportamento higroscópico através das Isotermas de sorção (Cavalcante et al., 2018), a qual segundo Martins et al., (2015) representa a relação entre a atividade de água e 
SILVA, J. N. et al.

umidade de um alimento, a uma temperatura constante.

Através do processamento de alimentos, novos produtos podem ser desenvolvidos com alto valor agregado e praticidade. Além disso, o processo de secagem é uma tecnologia de preservação mais usada no mundo por garantir uma maior shelf-life e reduzir o teor de umidade e a atividade da água nos alimentos para impedir o desenvolvimento microbiológico (SANTOS et al., 2015).

A vida útil corresponde ao período em que o alimento é armazenado sob certas condições que podem reter suas propriedades sensoriais, microbianas e físico-químicas. A estabilidade desses produtos é afetada pelos seguintes fatores: processo de preservação, atividade de umidade, material de embalagem e natureza dos alimentos (CORRÊA et al., 2015).

A embalagem desempenha um papel fundamental no armazenamento, transporte e manutenção da qualidade dos alimentos durante sua vida útil. O plástico é tradicionalmente usado como embalagem, devido às boas propriedades mecânicas, baixo custo e baixa permeabilidade ao vapor de água e alta compatibilidade com diferentes alimentos (GARAVAND et al., 2017; HONG et al., 2017).

Atrelado ao processo de secagem, a utilização de embalagens são de extrema relevância devido melhorar o manuseio, armazenamento e transporte, bem como garantir a preservação das características nutricionais e microbiológicas do produto. Dessa forma para garantir a sanidade e qualidade dos frutos, a escolha do tipo de material utilizado na embalagem é de extrema importância (LORENZI et al., 2014).

Diante disto, a crescente preocupação com desperdício de frutas em relação às questões ambientais, e a importância do reaproveitamento destas com tecnologias avançadas, baseadas nos impactos causados pela desidratação e uso de embalagens eficientes na conservação dos produtos, o presente estudo visou elaborar uva-passa (Arra $15^{\prime}($ ) analisando a composição físico-química e avaliando a isoterma de sorção dela à partir do armazenamento em diferentes embalagens.

\section{Material e Métodos}

\section{Matéria-prima}

Para realização do presente trabalho foram utilizadas uvas de variedade Arra $15^{\prime}{ }^{\circledR}$ doadas pela Fazenda Esperança, localizada no Projeto Senador Nilo Coelho, Núcleo 4, Petrolina-PE. Os frutos maduros e considerados como de "descartes" pela fazenda foram imediatamente transportados para o Laboratório Experimental de Alimentos (LEA) do Instituto 
SILVA, J. N. et al.

Federal de Educação, Ciência e Tecnologia do Sertão Pernambucano (IF Sertão-PE), onde foram selecionados e higienizados em solução clorada.

\section{Caracterização Físico-química}

Após a higienização, foram retiradas amostras das uvas para a caracterização in natura e após 30 dias de armazenamento, sendo avaliadas quanto ao teor umidade, $\mathrm{pH}$, sólidos solúveis, acidez total titulável e cor, conforme metodologias descritas em IAL (2008).

\section{Secagem}

Primeiramente as uvas foram pesadas em balança analítica, logo após foi realizada a pesagem e o tratamento químico com hidróxido de sódio à $1 \%$ por 30 segundos, em fervura, e assim colocadas no secador Air Fryer.

\section{Armazenamento}

Após a secagem das amostras, estas foram armazenadas em embalagens de polietileno de baixa densidade (PEBD) e em bandejas de poliestireno (PS) com auxílio do filme de cloreto de polivinila (PVC).

\section{Isoterma de Sorção}

As isotermas de sorção foram realizadas de acordo com a metodologia descrita por Coelho e Azevedo (2013), para avaliar a embalagem mais adequada para o armazenamento de uvas passas. As uvas-passas colocadas nas embalagens de PEBD e PS+PVC foram pesadas, e em seguida transferidas para os frascos de vidro contendo soluções salinas saturadas.

\section{Análise estatística}

Os resultados das análises foram avaliados pela análise descritiva, teste shapiro-wilk para normalidade, seguido de teste ANOVA, utilizando-se o programa Biostat 5.0.

\section{Resultados e Discussão}

Os valores obtidos a partir da triplicata das análises centesimais das uvas in natura, antes do processo de secagem e pré-tratamento com $\mathrm{NaOH}$, estão destacados na Tabela 01 .

O teor de umidade encontrado na uva in natura é aceitável, pois é uma fruta com uma grande quantidade de água, entretanto é importante observar que fatores como região, 
SILVA, J. N. et al.

maturidade, características do solo, clima e época de colheita também interferem nas propriedades físicas e químicas da fruta. (MORZELLE et al., 2015).

Tabela 1. Caracterização físico-química in natura da uva Arra 15’`®.

\begin{tabular}{|c|c|c|}
\hline \multicolumn{2}{|c|}{ Análise } & Resultados \\
\hline \multicolumn{2}{|c|}{ Umidade $(\%)$} & $79,27 \pm 0,02$ \\
\hline \multicolumn{2}{|c|}{$\mathrm{pH}$} & $3,5 \pm 0,01$ \\
\hline \multicolumn{2}{|c|}{${ }^{\circ}$ Brix } & $19,3 \pm 0,36$ \\
\hline \multicolumn{2}{|c|}{ Acidez Titulável } & $7,9 \pm 0,04$ \\
\hline & $\mathrm{L}^{*}$ & $43,6 \pm 1,34$ \\
\hline \multirow[t]{2}{*}{ Cor } & $a^{*}$ & $-5,01 \pm 0,15$ \\
\hline & $\mathrm{b}^{*}$ & $42,8 \pm 3,59$ \\
\hline
\end{tabular}

Fonte: Própria (2020).

$\mathrm{O} \mathrm{pH}$ dos alimentos é uma característica que depende de vários fatores, entre eles, o estado de preservação e condições das matérias-primas utilizadas, com isso o pH encontrado para a uva in natura é ótimo do ponto de vista microbiológico.

Segundo Brasil (2018) uvas destinadas ao processamento devem-se ter no mínimo $14^{\circ}$ Brix, assim a Arra $15^{\prime}{ }^{\circledR}$ utilizada encontra-se acima do valor estabelecido, estando adequada para o processo.

Em relação a acidez titulável, o valor encontrado é significativo, comparando com outras variedades, tendo em vista que a produção de ácidos orgânicos está ligado com a região e ao clima durante o crescimento e amadurecimento das uvas (ZERAVIK et al., 2016).

A cor é um importante atributo de qualidade de frutas frescas e processadas, pois ela está muito relacionada à aceitação dos alimentos pelo consumidor, sendo o aspecto visual o principal fator decisivo na escolha de um produto (RIBEIRO et al., 2012), com isso a coloração do produto ao final do processo deve ser semelhante a cor natural.

As determinações físico-químicas ( ${ }^{\circ} \mathrm{Brix}, \mathrm{pH}$, acidez e cor) foram realizadas após 30 dias, para cada embalagem específica, comparando assim os resultados entre elas.

Os dados amostrais foram tratados estatisticamente, analisando a normalidade pelo teste de Shapiro-wilk com nível de significância de $\mathrm{p}<0,05$. Seguido da análise descritiva quantitativa e teste ANOVA. Os resultados obtidos estão descritos abaixo na Tabela 2. 
SILVA, J. N. et al.

Tabela 2. Análise estatística das propriedades físico-químicas das uvas-passas nas embalagens de Ps+PVC e PEBD, após 30 dias de armazenamento.

\begin{tabular}{cccccc}
\hline \multirow{2}{*}{ Análise } & \multicolumn{2}{c}{$\mathrm{X}$} & \multicolumn{2}{c}{$\mathrm{CV}(\%)$} & \multirow{2}{*}{ Valor de P } \\
\cline { 2 - 5 } & Ps+PVC & PEBD & Ps+PVC & PEBD & \\
\hline Brix & $55 \mathrm{a} \pm 0,0$ & $53,3 \mathrm{a} \pm 1,1$ & - & 2,17 & \\
$\mathrm{pH}$ & $3,0 \mathrm{a} \pm 0,0$ & $3,0 \mathrm{a} \pm 0,0$ & - & 0,0 & $4 \%$ \\
Acidez & $2,0 \mathrm{a} \pm 0,0$ & $2,0 \mathrm{a} \pm 0,0$ & - & 0,0 & \\
Umidade & $78,6 \mathrm{a} \pm 8,6$ & $77,9 \mathrm{~b} \pm 2,2$ & 11 & 2,8 & \\
\hline
\end{tabular}

Fonte: Própria (2020).

Comparando as duas embalagens utilizadas, pode-se observar que os valores de ${ }^{\circ} \mathrm{Brix}$ não apresentaram diferença significativa entre elas, mostrando valores médios confiáveis por apresentarem desvio padrão e coeficiente de variação reduzidos (não ultrapassando 10\%). Ainda, segundo o teste de Shapiro-Wilk a dispersão dos valores foi normal. O pré-tratamento com $\mathrm{NaOH}$ não influenciou significativamente no teor de sólidos solúveis, tendo em vista que o processo de secagem concentrou mais esses compostos.

Sabe-se que o potencial hidrogeniônico é um dos parâmetros mais importantes de avaliação dos alimentos, uma vez que indica se os produtos estão seguros em relação ao crescimento de microrganismos. Notou-se que não houve diferenças significativas deste parâmetro, bem como o pré-tratamento com $\mathrm{NaOH}$ não alterou significativamente os valores de $\mathrm{pH}$ durante o período de armazenamento. Em comparação com a literatura, foram encontrados valores semelhantes entre 3,5 e 4,5 no estudo feito por Costa (2015), o qual realizou a desidratação de uvas 'Itália' pré-tratadas com a mesma substância.

A uva na sua forma in natura possui uma acidez elevada, tal propriedade permaneceu na uva-passa, sendo que o teor de acidez pode apontar o estado de conservação de um alimento, estando relacionada a presença de ácidos orgânicos encontrados naturalmente em frutas e vegetais como os ácidos málico, cítrico e tartárico, sendo esse último predominante na uva (RIBEIRO et al., 2016). Durante o período de armazenamento pôde-se observar que não houve uma mudança significativa das suas quantidades nas uvas-passas, tanto na Ps+PVC como na PEBD, mostrando que as embalagens utilizadas e o pré-tratamento, não alteraram a acidez do produto.

A umidade é um dos principais parâmetros, relacionados à qualidade da uva-passa, uma vez que a sua quantidade influencia diretamente na concentração de nutrientes e fito químicos bioativos (DOYMAZ, 2006). A umidade final apresentou que houve uma perda de água após o 
SILVA, J. N. et al.

processo de secagem em ambas embalagens, sendo que a embalagem PEBD uma melhor redução deste parâmetro.

Os valores da análise de cor a partir dos parâmetros $L^{*}, a^{*}$ e b* das uvas armazenadas após o processo de secagem e pré-tratamento com $\mathrm{NaOH}$, estão destacados na Tabela 3.

Tabela 3. Variação da cor das uvas em cada embalagem ao decorrer do tempo.

\begin{tabular}{cccccccc}
\hline \multirow{2}{*}{$\begin{array}{c}\text { Período de } \\
\text { armazenamento }\end{array}$} & \multicolumn{3}{c}{ Ps + PVC*$^{*}$} & \multicolumn{3}{c}{ PEBD* } & \multicolumn{2}{c}{ Valor de P } \\
\cline { 2 - 7 } & $\mathrm{L}^{*}$ & $\mathrm{a}^{*}$ & $\mathrm{~b}^{*}$ & $\mathrm{~L}^{*}$ & $\mathrm{a}^{*}$ & $\mathrm{~b}^{*}$ & \\
\hline 30 dias & $17,8 \mathrm{a}$ & $3,0 \mathrm{a}$ & $2,5 \mathrm{a}$ & $17,2 \mathrm{a}$ & $2,6 \mathrm{a}$ & $1,9 \mathrm{a}$ & \\
\hline
\end{tabular}

Valores obtidos através da respectiva análise em triplicata.

Fonte: Própria (2020).

Os valores de Luminosidade não apresentaram diferença significativa entre as embalagens e tratamento utilizados, assim como as coordenadas $\mathrm{a}^{*} \mathrm{e} \mathrm{b}^{*}$, mostrando que os dois métodos tiveram efeitos similares, em relação a mudança de cor, no produto ao final de 30 dias de armazenamento.

A partir do diagrama de cores (Figura 1) junto com valores obtidos na análise por calorimetria, é possível diagnosticar a cor final do produto nas duas embalagens.

Figura 1. Diagrama de cor.

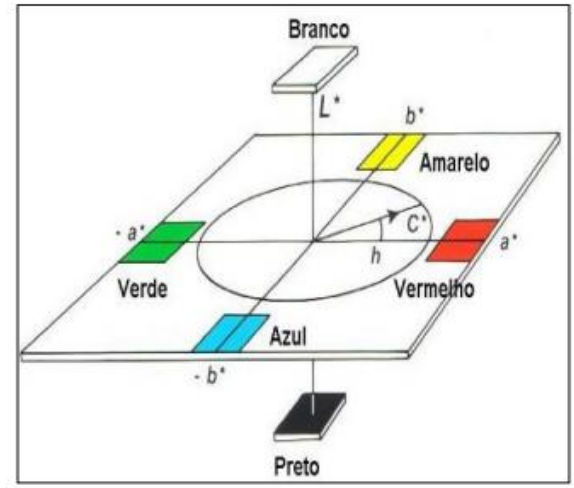

Fonte: Hunter Lab (2019).

Após avaliação de dados, e comparação no diagrama pôde-se verificar a coloração da uva passa (Figura 2). De acordo com os resultados obtidos, durante o armazenamento houve a intensificação do escurecimento da uva passa, porém sem um efeito significativo no parâmetro $L^{*}$ em relação ao processo de secagem e pré-tratamento empregado. Quanto aos valores encontrados para a coordenada $a^{*}$ que indica a cor para tons de vermelho e verde e para 
coordenada $b^{*}$ que reflete a mudança de tons entre o amarelo e azul, esta foi influenciada pelo tempo de armazenamento em ambas embalagens.

Figura 2. Determinação da cor das uvas passas.

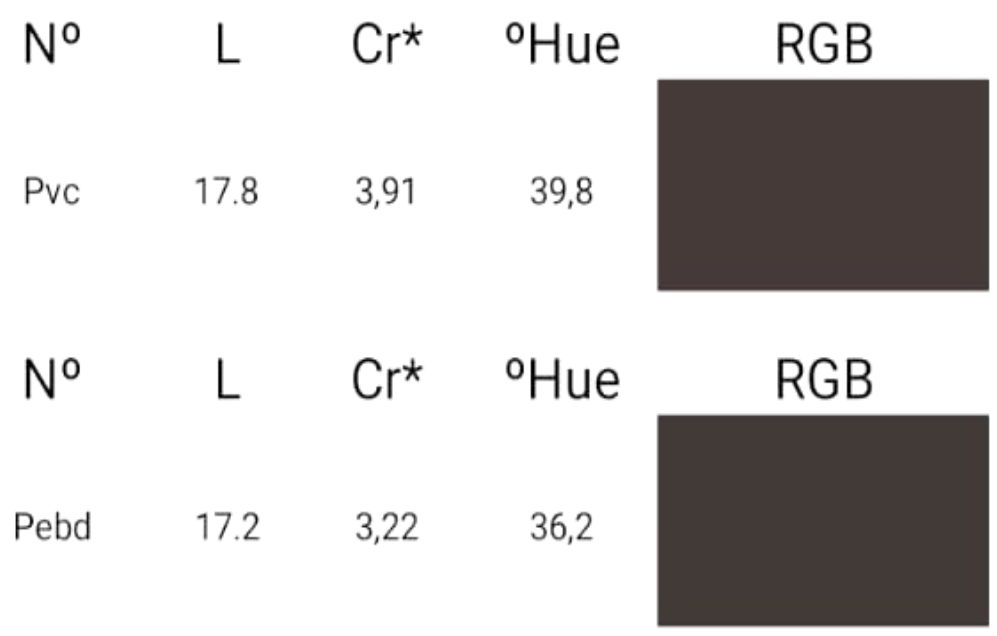

Fonte: Aplicativo Análise de cor (Research Lab Tools).

Os resultados referentes às variações de peso de Isoterma das uvas-passas nas embalagens Ps+PVC e PEBD estão representadas abaixo nas Figuras 3 e 4.

A partir dos valores obtidos em ambas embalagens, (Figuras 3 e 4) pôde-se verificar que houve perda de massa na maioria dos frascos, pré-tratadas quimicamente na air fryer, na temperatura utilizada, influenciando consequentemente na diminuição da umidade, indicando assim a seguridade do produto quanto ao crescimento microbiano, além de reações oxidativas, shelf-life e qualidade final.

Figura 3. Variação do peso de isoterma das Uvas-passas, em Ps + PVC, no início e fim de armazenamento.

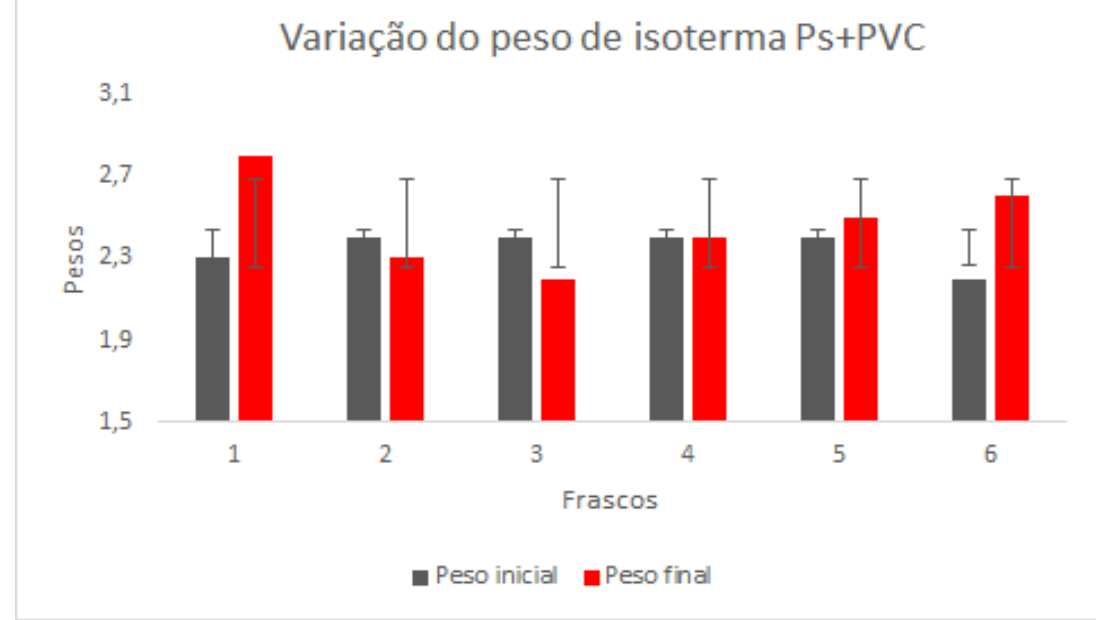

Fonte: Própria (2020).

[132] 
SILVA, J. N. et al.

Figura 4. Variação do peso de isoterma das Uvas-passas, em PEBD, no início e fim de armazenamento.

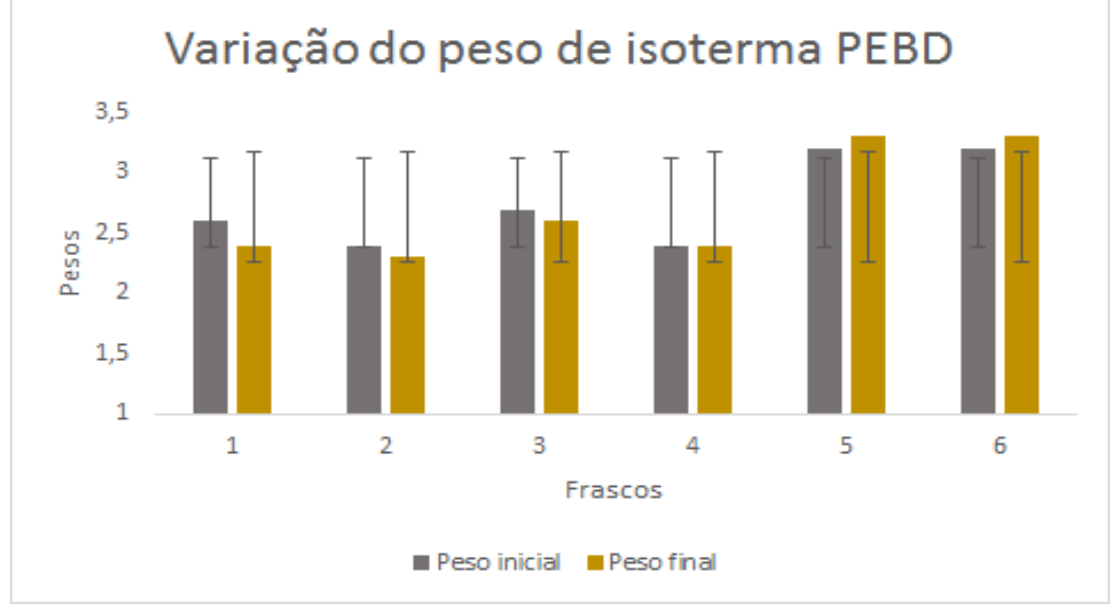

Fonte: Própria (2020).

Os resultados referentes a Isoterma de sorção das uvas-passas nas embalagens Ps+PVC e PEBD está representada abaixo na Figura 5.

Figura 5. Valores da isoterma de sorção das uvas-passas nas duas embalagens utilizadas.

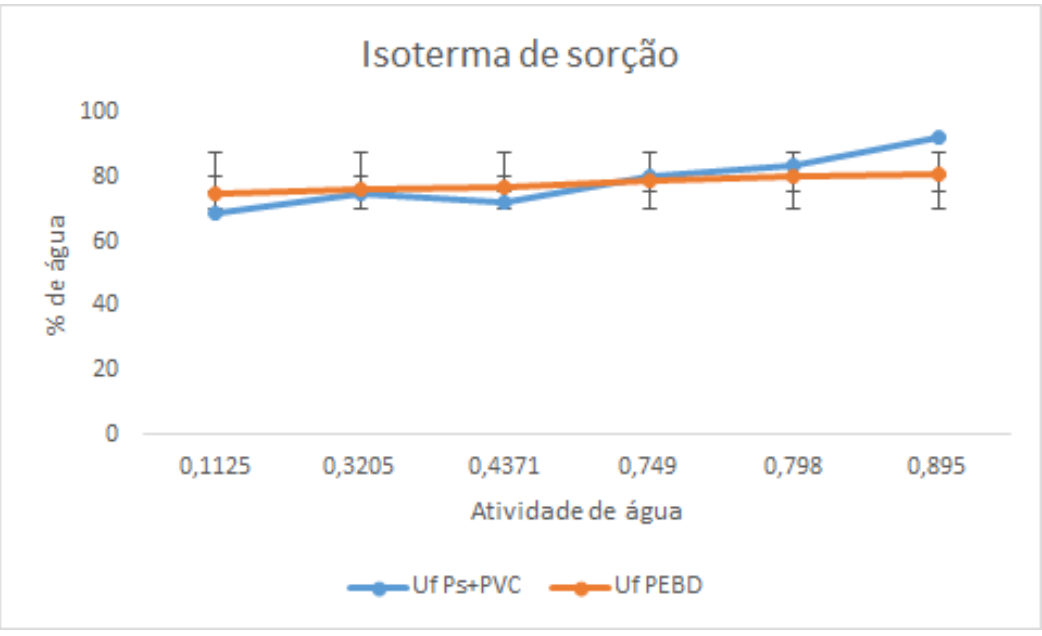

Fonte: Própria (2020).

Após trinta dias de estabilização as isotermas foram adquiridas, observou-se que o processo de secagem reduziu a umidade inicial $(79,27 \%)$ para $24 \%$ posteriormente, influenciando na quantidade de água no produto, evitando que haja crescimento de microrganismos e promovendo uma maior concentração de nutrientes e compostos. De acordo com Wang (2016) vários pré-tratamentos, incluindo tratamentos químicos, físicos e de branqueamento, têm sido realizados para remover a camada de cera dos frutos antes do processo de secagem. Todos os resultados indicaram que a taxa de secagem aumenta e o tempo de secagem diminui, para que as uvas atinjam a umidade segura necessária para o armazenamento. 
SILVA, J. N. et al.

Dessa forma, o pré-tratamento com o $\mathrm{NaOH}$ utilizado, influenciou em um período de secagem menor, devido a temperatura aplicada, proporcionando uma umidade constante em menor tempo.

A partir da estatística realizada, as embalagens utilizadas apresentaram diferenças significativas do teor de umidade nas uvas-passas, com isso observou-se que a embalagem de PEBD demonstrou um menor índice de adsorção de água e consequentemente um maior de dessorção, resultando em dados mais constantes (Figura 5).

\section{Conclusões}

A partir da análise físico-química na uva (Arra $\left.15^{\prime}{ }^{\circledR}\right)$ in natura, conclui-se que a fruta, possui propriedades suficientes para o processo de fabricação de uvas-passas, além disso a utilização do refugo diminui o descarte e consequentemente o desperdício, obtendo-se assim um produto com valor agregado.

Ao final do armazenamento, averiguou-se que a composição centesimal, exceto a umidade, não foi alterada de forma significativa, após a secagem, continuando a ter propriedades suficientes para a elaboração de uvas-passas.

A utilização do pré-tratamento com $\mathrm{NaOH}$ foi satisfatória, quanto a velocidade de secagem, além de não modificar, significativamente, as propriedades físico-químicas.

Entre as embalagens utilizadas, a de PEBD foi a que apresentou resultados mais satisfatórios em relação às isotermas de sorção.

Aconselha-se a utilização de outros pré-tratamentos e de maiores tempos de armazenagem, bem como o uso de outras técnicas de secagem, uma vez que a uva Arra $15^{\prime}($ é uma variedade nova na região do Submédio do Vale do São Francisco e apresenta boas propriedades para a formulação de novos subprodutos.

\section{Referências}

ABRAFRUTAS - Associação Brasileira dos Produtores Exportadores de Frutas e Derivados. Dados estatísticos do setor: Estatísticas das exportações de frutas em 2019.

ALAMAR, P. D.; CARAMÊS, E. T. S.; POPPI, R. J.; PALLONE, J. A. L. Quality evaluation of frozen guava and yellow passion fruit pulps by NIR spectroscopy and chemometrics. Food Research International, v. 85, n. 7, p. 209-214, 2016. 
ARAÚJO, R. D. F.; VILAR, S. B. O.; BARROS, E. R. Kinetics of Drying and PhysicalChemical Quality of Peach cv. Hubimel. Journal of Agricultural Science, 11(16), 223-232. 2019.

CAVAlCANTE, C. E. B.; ROdRIGUES, S.; AFOnSO, M. R. A.; COSTA, J. M. C. Comportamento Higroscópico da Polpa de Graviola em Pó Obtida Por Secagem em Spray Dryer, Brazilian Journal of Food Technology, Vol 21, 2018.

COSTA, J. D. S.; FIGUEIREDO NETO, A.; NUNES, S. M.; RYBKA, A. C. P.; BIASOTO, A. C. T.; FREITAS, S. T. Caracterização física e físico-química de uva Itália desidratada. Revista Iberoamericana de Tecnología Postcosecha, v. 16, n. 2, p. 273-280, 2015.

COSTA, J. D. S.; FIGUEIREDO NETO, A.; NUNES, S. M.; RYBKA, A. C. P.; BIASOTO, A. C. T.; FREITAS, S. T. Caracterização física e físico-química de uva Itália desidratada. Revista Iberoamericana de Tecnología Postcosecha, v. 16, n. 2, p. 273-280, 2015.

EMPRAPA. Ciência que transforma: Resultados e impactos positivos da pesquisa agropecuária na economia, no meio ambiente e na mesa do brasileiro. 2019. Disponível em: $<$ https://www.embrapa.br/grandes-contribuicoes-para-a-agricultura-brasileira/frutas-ehortalicas>. Acesso em 03/08/2020.

FEIDEN, A.; FEIDEN, A.; GALVANI, F.; CAMPOLIN, A. Desidratação de frutas utilizando secador solar. Corumbá: Embrapa Pantanal, 2015. 5 p. (Comunicado Técnico 98). Disponível em: 〈https://www.infoteca.cnptia.embrapa.br/infoteca/bitstream/doc/1037117/1/COT98.pdf $>$.

FEIDEN, A.; FEIDEN, A.; GALVANI, F.; CAMPOLIN, A. Desidratação de frutas utilizando secador solar. Corumbá: Embrapa Pantanal, 2015. 5 p. (Comunicado Técnico 98). Disponível em: 〈https://www.infoteca.cnptia.embrapa.br/infoteca/bitstream/doc/1037117/1/COT98.pdf $>$.

GARAVAND, F.; ROUHI, M.; RAZAVI, S. H.; CACCIOTTI, I.; MOHAMMADI, R. Improving the integrity of natural biopolymer films used in food packaging by crosslinking approach: A review. International Journal of Biological Macromolecules, v. 104, p. 687-707, 2017. 
GAVA, A. J; FRIAS, J. R.G; SILVA, C.A.B. Tecnologia de alimentos: princípios e aplicações. São Paulo: Nobel, 2008.

HONG, J.; CHEN, Y.; WANG, M.; YE, L.; QI, C.; YUAN, H.; ZHENG, T.; LI, X. Intensification of municipal solid waste disposal in China. Renewable and and Sustainable Energy, v. 69, p. 168-176, 2017.

KARNIEL, E. S.; GIUMARRA, E. S. Grape Plant Named “Arrafifteen”e. US Pat. 2011/0219502 P1, 8 set, 2011. 4p.

LEÃO, P. C. de S.; BRANDAO, E. O.; GONCALVES, N. P. da S. Caracterização agronômica e molecular do clone Itália Muscat no Submédio do Vale do São Francisco.

LOPES, R.L.T. Dossiê técnico: conservação de alimentos. Fundação tecnológica de Minas Gerais, CETEC, 2007.

MARTINAZZO, A. P.; CORRÊA, P. C.; RESENDE, O.; MELO, E. C. Análise e descrição matemática da cinética de secagem de folhas de capim limão. Revista Brasileira de Engenharia Agrícola e Ambiental, v. 11, n.3, p.301- 306, 2007.

MARTINS, M. G.; MARTINS, D. E. G.; PENA, R. S. Drying Kinetics and Hygroscopic Behavior of Pirarucu (Arapaima Gigas) Fillet with Different Salt Contents, LWT - Food Science and Technology, Vol 62, p. 144-151. 2015.

MORZELLE, M. C., BACHIEGA, P., SOUZA, E. C., VILAS BOAS, E. V. B., LAMOUNIER, M. L. Caracterização química e física de frutos de curriola, gabiroba e murici provenientes do cerrado brasileiro. Revista Brasileira de Fruticultura, 37, 96- 103. 2015.

NESPOLO, C. R. et al. Práticas em tecnologia de alimentos. Porto Alegre: Artmed. Produced by Deep Fat Frying and Air Frying. Journal of Food Science. Vol. 80, Nr. Revista Brasileira de Fruticultura, Jaboticabal, v. 33, n. 1, p. 297-302, mar. 2015.

SANTOS, N. C.; BARROS, S. L.; MONTEIRO, S. S.; SILVA, S. N.; RIBEIRO, V. H. A.; SILVA, V. M. A.; GOMES, J. P.; SANTIAGO, A. M.; LUIZ, M. R.; VIEIRA, D. M.; 
RIBEIRO, T. P.; LIMA, M. A. C.; ALVES, R. E. Maturação e Qualidade de Uvas para Suco em Condições Tropicais, nos Primeiros Ciclos de Produção. 2015.

TERUEL, M. de. R. et al. A Comparative Study of the Characteristics of French Fries, 2015. VITIBRASIL. Dados da vitivinicultura. Brasília: Embrapa, 2016. Disponível em: $<$ http://vitibrasil.cnpuv.embrapa.br/index.php?sopcao=sopt_05\&opcao=opt_05>.

WANG, J., MUJUMDAR, A. S., MU, W., FENG, J., ZHANG, X., ZHANG, Q., FANG, X., GAO, Z., AND XIAO, H. Grape Drying: Current Status and Future Trends. In MORATA, A.; LOIRA, I. Grape and Wine Biotechnology, In Tech Open; 2016.

ZERAVIK, J.; FOHLEROVA, Z.; MILOVANOVIC, M.; KUBESA, O.; ZEISBERGEROVA, M.; LACINA, K.; PETROVIC, A.; GLATZ, Z.; SKLADAL, P. Various instrumental approaches for determination of organic acids in wines. Food Chemitry, v. 194, p. 432-440, 2016. 